\title{
El ayuno, signo de identidad grupal en la Didajé (Did 8,1)
}

\section{DAVID Álvarez Cineira}

RESUMEN: Las instrucciones rituales de la Didajé $(8,1-3)$ referentes al ayuno comunitario bisemanal (miércoles y viernes) y el empleo de una oración distintiva sirvieron para demarcar y remarcar las fronteras de este grupo de pertenencia cristiano frente a otros grupos judíos en competencia. Mediante la descalificación del grupo rival con el calificativo peyorativo de "hipócritas", su autor pretende mantener la unidad y cohesión de su grupo frente a la atracción que ejercían esos grupos judíos rivales y potenciar la identidad intergrupal.

Palabras Clave: Didajé, ayuno, identidad, hipócritas.

ABSTRACT: The ritual instructions of the Didache $(8,1-3)$ concerning the biweekly communal fast (Wednesdays and Fridays) and the use of a distinctive prayer served to demarcate and highlight the borders of this Christian group in front of other competing Jewish groups. By disqualifying the rival group with the pejorative term "hypocrites", the author intends to maintain the unity and cohesion of his group in the face of the attraction exercised by these rival Jewish groups and to enhance intergroup identity.

KEYwORDS: Didache, fasting, identity, hypocrites.

Las teorías de identidad social, y en concreto los estudios sobre la interacción entre las relaciones intergrupales y los procesos intragrupales, sugieren que una forma efectiva de mantener la solidaridad grupal es mediante la comparación con grupos ajenos, lo que mejora la valoración positiva de los miembros del grupo. La mera existencia de un grupo externo 
puede aumentar la autoestima de los miembros y su cohesión interna. Por otro lado, cuando la comunidad se ve desafiada por ataques de grupos externos o la atracción de esos grupos amenaza con debilitar la identidad o la solidaridad de los miembros del grupo de pertenencia, entonces se requieren estrategias para recuperar el carácter distintivo positivo del grupo y reajustar la relación entre el grupo de pertenencia y el grupo externo para evitar que se desintegre. Así pues, clarificar la relación de un grupo de pertenencia con los grupos externos constituye una medida importante para mantener la cohesión del grupo.

En la Didajé, los límites grupales se definen principalmente por las tradiciones de Jesús y los rituales de la comunidad. La aceptación de las primeras y la participación en los segundos proporcionan los criterios básicos para distinguir a un insider de un outsider. Las dificultades experimentadas reciben un valor positivo al considerarlas el precio a pagar por esta forma de vida. En respuesta a las amenazas de varios grupos, la Didajé intenta trazar las fronteras de la comunidad frente a la sociedad pagana y a los judíos no cristianos, de tal forma que aísla a sus seguidores frente a grupos rivales y minimiza las influencias negativas en los miembros de su comunidad. Todas estas estrategias para trazar fronteras grupales en la Didajé sirven para mantener la solidaridad del grupo en medio de las tensiones que experimenta.

Además, las instrucciones rituales en la Didajé desempeñan una función importante en la cohesión grupal. Al realizar reiteradamente los rituales comunitarios, a los miembros se les recuerda continuamente sus privilegios como pueblo de Dios y experimentan la unidad del grupo. Esto aumenta el compromiso de los miembros con el grupo de pertenencia, especialmente en los aspectos cognitivos y emocionales.

Aunque no proporciona una enseñanza integral, la sección ritual de la Didajé contiene instrucciones selectivas sobre los rituales de iniciación (bautismo: Did 7) y de pertenencia (la eucaristía: Did 9-10), así como sobre otros ritos que contribuyen a configurar la identidad y la diferenciación frente a otros grupos afines: el ayuno y las oraciones (Did 8). Dicha naturaleza selectiva sugiere que estas directrices intentaban responder a problemas reales de la comunidad y nos revelan rasgos de la identidad de las comunidades destinatarias del documento. Aquí nos limitaremos al ritual del ayuno como signo de identidad grupal. 


\title{
1. El ayuno comunitario
}

Tras las indicaciones sobre el bautismo y tal vez por asociación con el tema del ayuno prebautismal (Did 7,4) $)^{1}$, la Didajé instruye acerca de otros dos rituales que sus comunidades debían realizar en contraste con

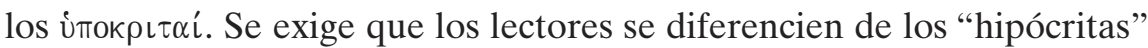
al observar diferentes días de ayuno y mediante el empleo de una oración distintiva, el Padre nuestro, que se debe recitar tres veces al día. El tenor de las directivas dice así:

\begin{abstract}
"Vuestros ayunos no sean al tiempo que lo hacen los hipócritas, pues estos ayunan el segundo y el quinto día de la semana; vosotros, empero, ayunad el día cuarto [miércoles] y el de la preparación [viernes]. Tampoco oréis a la manera de los hipócritas, sino que tal como el Señor lo mandó en su Evangelio, así oraréis: Padre nuestro... Así oraréis tres veces al día” (8,1-3).
\end{abstract}

Como regulación grupal, señalada mediante el imperativo, el primer versículo $(8,1)$ no parece plantear ninguna dificultad. Sin embargo, ha sido fuente de debate durante gran parte de su historia. Partiendo del desinterés de Jesús por las cuestiones rituales y, en concreto, por el ayuno (Mt 9,15), y del rechazo de Pablo hacia las normas alimentarias rituales (Rom 14,1-22; 1 Cor 10,23-31; Col 2,16), muchos estudiosos del cristianismo primitivo de los siglos XIX y XX adujeron que la Didajé debía ser un documento tardío que refleja el proceso de ritualización del cristianismo durante el siglo II d.C., ya que el cristianismo naciente se oponía a la noción misma de ritual. Sin embargo, los ritos no fueron secundarios, sino determinantes para la configuración de la identidad del cristianismo naciente, tal y como subrayan los estudios modernos.

Este pasaje constituye la certificación más antigua de un ayuno de dos días por semana y se convirtió en una referencia clásica para muchas constituciones eclesiales posteriores que exigían el ayuno el miércoles y el viernes. Pero a diferencia de esas constituciones, la Didajé no aduce ninguna motivación cristológica o de piedad, ni menciona el día de la pasión

\footnotetext{
${ }^{1}$ Para el ayuno como preparación bautismal, cf. D.A. Cineira, "El ayuno en la Didajé", EstAg 54 (2019) 27-49.
} 
para justificar el ayuno del viernes. Asume la existencia de un ayuno bisemanal por parte de la comunidad como praxis establecida y valorada, y como elemento intrínseco de su disciplina religiosa. La preocupación radica en realizar lo que se estima correcto, sin justificar por qué se debe ayunar. Además, este tipo de ayuno grupal público contribuyó, como después veremos, a proporcionar al grupo una identidad distintiva frente a otros grupos que tenían la misma praxis, aunque se estipula que se regularice en días diferentes para remarcar dicha diferenciación entre la comunidad de la Didajé y el grupo rival, cuyos miembros son descritos como "hipócritas". ¿Quiénes son esos rivales?²

\section{Los días de ayuno}

Uno de los pocos indicios que nos aporta el texto para la identificación de los competidores se refiere a sus días de ayuno. Es claro que se trata de un grupo judío, pues la Didajé emplea el concepto de día de la preparación para referirse al día previo al Sabbat y contabiliza los días conforme al calendario judío, según el cual los días de la semana no tienen nombres, sino que se enumeran a partir del Sabbat. En los calendarios griegos y romanos no existía el concepto de semana, ni el Sabbat judío, día de descanso. A finales del s. I d.C., los romanos adoptaron la semana de 7 días ${ }^{3}$, que iniciaba con el día de Saturno (en inglés todavía se conserva ese origen: Saturday) y correspondía al séptimo día de la semana judía. En el siglo II d.C. se trasladó el inicio de la semana al día del Sol (Sunday), coincidiendo así las semanas judía y romana. En esa época todavía no estaba establecido un día festivo determinado o de descanso. El domingo adquirirá relevancia con Constantino ${ }^{4}$, convirtiéndose en el s. VI en día

${ }^{2}$ D.A. Cineira, "Die Didache im Formationsprozess des frühen Christentums", en: Giancarlo Collet - Dorothea Sattler (Hrgs.), In Konflikten leben: Mit Zorn und Zärtlichkeit an der Seite der Armen. Ein Beitrag zur ökumenischen Dekade zur Überwindung von Gewalt, Lit Verlag, Münster 2012, 125-129.

${ }^{3}$ Jörg Rüpke, The Roman Calendar from Numa to Constantine Time, History and the Fasti, Blackwell Publishers, Malden, MA - Oxford 2011, 109-134.

${ }^{4}$ Renee Michele Salzman, On Roman Time: The Codex-calendar of 354 and the Rhythms of Urban Life in Late Antiquity, University of California Press, Berkeley - Los Angeles - Oxford 1990. 
oficial de descanso. Aunque la Didajé había abandonado la observancia del sábado judío para sus celebraciones cúlticas (Did 14), el ritmo de los ayunos y las oraciones de este movimiento de Jesús continuaban siendo computados conforme al sistema judío, por lo que los gentiles, que se adherían a las comunidades de la Didajé, tenían que familiarizarse con este tipo de calendario.

\section{1. El ayuno de los hipócritas: el segundo y quinto día de la semana}

Según el texto, estos hipócritas ayunan el segundo y el quinto día de la semana, es decir, los lunes y los jueves. Si conociéramos la existencia de algún grupo judío que ayunara precisamente esos días, entonces tendríamos algún firme candidato para la identificación de los hipócritas. Lucas, en la perícopa del fariseo y el publicano, nos informa que el fariseo se siente orgulloso de incluir en su oración dirigida a Dios la praxis del ayuno realizada dos días por semana (Lc 18,12). Asimismo, Mc 2,18-22 sugiere que los fariseos, al igual que los discípulos de Juan el Bautista, eran conocidos por los ayunos.

Únicamente el día de Yom Kippur constituía el día de ayuno obligatorio para todos los judíos. No obstante, los textos bíblicos recogen otro tipo de ayunos ${ }^{5}$, los cuales se mencionan con más frecuencia en los escritos del Segundo Templo y en los escritos rabínicos. El ayuno voluntario se practicaba frecuentemente como señal de devoción y jugó un papel importante en la vida religiosa judía del siglo I d.C. ${ }^{6}$ Sin embargo, no se con-

${ }^{5}$ Ejemplos de ayunos: (a) ayuno después de una muerte (2 Sam 1,12;12,16-23); (b) ayuno de guerra (1 Sam 14,24); (c) ayuno preparatorio o introductorio (Ex 34,28; Juec 20,26; 1 Sam 27,20; 1 Rey 21,9); (d) el ayuno como auxiliar de la oración, en particular de una oración de intercesión (1 Sam 7,5s; 2 Sam 12; Neh 1,4s.); (e) ayuno expiatorio (1 Sam 7,6; Jer 36,9; Joel 2,12; Jonás 3); (f) los denominados ayunos de Zacarías (Zac 8,19); (g) ayuno concomitante (Est 4,6), de quien se dice que ayunó para llorar la muerte de su marido todos los días, excepto la víspera del sábado, el sábado mismo, la víspera de la luna nueva, la luna nueva y otras festividades.

${ }^{6}$ S. Safrai, "Religion in Everyday Life", en: S. Safrai - M. Stern (eds.), The Jewish People in the First Century. Historical Geography, Political History, Social, Cultural and Religious Life and Institutions (CRINT I/2), Van Gorcum - Fortress Press, Assen/Maastricht -, $1987^{2}, 814-816$. En periodos de sequía, los ayunos tenían lugar generalmente en lunes, jueves y lunes siguiente. Al inicio, estos ayunos eran realizados por los sabios a nivel personal. Cf. Marcello del Verme, Didache and Judaism: Jewish Roots of an Ancient Christian-Jewish Work, New York - London 2004, 167, n. 51. 
servan documentos que afirmen la existencia de una ley que prescribiera la observancia de un ayuno bisemanal? Por este motivo, existen ciertas dudas acerca del carácter histórico de la presentación lucana $($ Lc 18,12) que atribuye este tipo de ayuno a los fariseos. Tal vez, esta costumbre se limitara a ciertos círculos entre los fariseos y sus discípulos, probablemente debida a la iniciativa privada de una persona piadosa, práctica que sería adoptada posteriormente por algún grupo judío ${ }^{8}$. La mayoría de los textos que mencionan el ayuno durante los lunes y los jueves son posteriores al año 70 d.C., aunque varios de ellos pudieran remontarse a fechas anteriores, como veremos a continuación (m.Táanit 2,9; t.Táanit 2,4.8).

¿Qué días podían ser elegidos para los ayunos a nivel privado y que posteriormente fueran asumidos por algún grupo? La Misná, en el tratado de Ta'anit ("los días de ayuno"), describe una práctica relacionada con el Templo conocida como ma 'amadôt. Su intención era involucrar a otros, además de los sacerdotes, en el ritual del sacrificio diario. Como se explica en un pasaje tannaítico que aparece en la Misná, aunque pudiera ser una interpolación, los miembros del ma'amad ayunaban de lunes a jueves: "Los componentes de la representación ayunaban cuatro días de la semana, desde el lunes hasta el jueves. En la vigilia del sábado no ayunaban por el honor debido al sábado. Tampoco (ayunaban) el primer día de la semana para no pasar del reposo y del regocijo al esfuerzo y al ayuno y provocase la muerte" ${ }^{\prime \prime}$.Ta'anit 4,3; cf. Judit 8,6). La lógica subyacente es que el sábado viene precedido y seguido de un día en que no se ayuna para que la persona no sufra los efectos nocivos que puedan resultar de pasar del ayuno al banquete o del banquete al ayuno. El texto deja entrever que las viandas del Sabbat eran de mejor calidad que las del resto de la semana. Los estudiosos debaten, no obstante, si esta práctica ya era común a finales del período del Segundo Templo o si se desarrolló solo después del año 70 d.C. Asimismo, la Misná comenta que un periodo de 3

\footnotetext{
${ }^{7}$ Hermann L. Strack - Paul Billerbeck, Kommentar zum Neuen Testament aus Talmud und Midrasch. C.H. Beck'sche Verlagsbuchhandlung, München 1956², I 426-429; II 241s., referente al ayuno público y privado.

${ }^{8}$ Según Marcello del Verme, Didache 167 s., se podría suponer que Lc 18,12b anticipa la distinción (rabínica) en el judaísmo entre dos tipos de personas, los haverim-fariseos y el publicano.

${ }^{9}$ La Misná, edición preparada por Carlos del Valle, Editorial Nacional, Madrid 1981, 392.
} 
días de ayuno no debe iniciar en el quinto día de la semana para no dañar los precios de los mercados ${ }^{10}$, por consiguiente una razón muy crematística.

Aunque el texto mencionado anteriormente aduce las razones para no ayunar los domingos y viernes ${ }^{11}$, sin embargo no aclara los motivos del ayuno de lunes a jueves. Será el talmud de Babilonia quien interprete esos días de ayunos como una serie de peticiones en nombre de grupos de población que se encontraban en situación de riesgo: "En el segundo día ayunaban por quienes bajaban al mar; en el tercer día, por quienes viajaban al desierto; en el cuarto día, para que la tosferina no atacara a los niños; en el quinto día, por las madres embarazadas y madres que amamantaban a sus hijos...; en el sexto, no ayunaban por respeto al Sabbat" (b.Ta'anit 27b).

La tradición rabínica parece que eligió el segundo y el quinto día en caso de necesitar decretar un ayuno público, pero sin señalar razones específicas para la elección de esas fechas. Por lo general, se intenta explicar mediante el hecho de que el lunes y el jueves, según las tradiciones talmúdicas, eran considerados desde tiempos inmemoriales días de asamblea comunitaria y de mercado semanal de las villas y ciudades. Esos días de mercado propiciaban que los habitantes de las aldeas acudieran a vender sus productos agrícolas o artesanales y adquirir bienes necesarios que no

${ }^{10}$ m.Ta'anit 2,9: "No se imponen ayunos a la comunidad que comiencen el jueves a fin de no producir un alza de precios, sino que los tres primeros ayunos han de tener lugar en lunes, jueves y lunes. Los otros tres ayunos han de tener lugar en jueves, lunes y jueves. R. Yosé dice: del mismo modo que los primeros no comienzan en jueves, así tampoco han de comenzar los segundos ni los últimos (en jueves)".

${ }^{11}$ Otras explicaciones para no ayunar en domingo vienen proporcionadas por los amoraim en b.Ta'anit 27b: “¿Cuál es la razón [por la que las ma’amadot no ayunaron el domingo?] R. Yohanan dijo: Debido a los cristianos. R. Samuel bar Nahmani dijo: Porque es el tercer día de la creación [por lo tanto, la humanidad y los seres humanos están débiles; ver m. Shabbat 9,6]. Resh Laqish dijo: Se otorga un alma extra al hombre en la víspera del Sabbat; después del Sabbat se la quitan". De forma semejante se expresa Soferim 17,4 (303): "Algunos dicen [que no hay ayuno ma'amad el domingo] porque durante el crepúsculo en la víspera de Sabbat cada israelita recibe un alma adicional y después de Sabbat, la toman de él”. Otra razón: "por los cristianos, para que no digan: 'Ellos están ayunando porque es nuestro día de celebración'”. Una baraita en el talmud de Jerusalén (y.Ta'anit 4,4, 68b) explica que el interdicto contra el ayuno, ya sea el domingo o el viernes, se debe al honor del Sabbat. 
podían obtener en sus pueblos ${ }^{12}$. Constituían momentos propicios y especiales para el encuentro y la comunicación, para la cohesión social. Se aprovechó la confluencia de gran parte de la población rural en las ciudades como excelente oportunidad para hacer uso del sistema judicial local que se reunía en los días de mercado ${ }^{13}$, aunque las tradiciones no aclaran explícitamente la elección de esos días para administrar justicia. Así mismo, se consideró un día propicio para la lectura de la Torá ${ }^{14}$ en el servicio sinagogal matutino o del Rollo de Ester (Meguilá) en la fiesta del Purim ${ }^{15}$. No obstante, según Ze'ev Safrai ${ }^{16}$, las tradiciones talmúdicas atestiguarían que ya en el período de Jamnia, los días de mercado del lunes y jueves habían perdido parte de su importancia y, aunque los habitantes de las aldeas continuaron dependiendo de la ciudad para la lectura de la

${ }^{12}$ Ben-Zion Rosenfeld - Joseph Menirav, Markets and Marketing in Roman Palestine (JSJSup 99), Brill, Leiden 2005, 43-45. Los mercados de las aldeas se celebraban los viernes. Paul F. Bradshaw, Daily Prayer in the Early Church: A Study of the Origin and Early Development of the Divine Office, ACC 63, SPCK, London 1981, 19. Véase también Jürgen K. Zangenberg, "Reconstructing the Social and Religious Milieu of the Didache: Observations and Possible Results", en: Huub van de Sandt - Jürgen K. Zangenberg (eds.), Matthew, James, and Didache. Three Related Documents in Their Jewish and Christian Settings (SBL Symposium 45), Society of Biblical Literature, Atlanta 2008, 56-57.

${ }^{13}$ (1) Los tribunales solían reunirse en las diferentes ciudades los lunes y jueves (m.Ketubbot 1,1; tb.Bava Kama 82a; t.Ta'anit 2,4). Esta práctica fue atribuida a Esdras. Ese dato no es un hecho histórico, pero sí indica que la práctica era bastante antigua. (2) Una virgen se casaba el miércoles (m.Ketubbot 1,1). La Misná declara que se eligió ese día para permitir que el esposo pudiera presentar una denuncia al día siguiente en el tribunal si descubría que su esposa no era virgen.

${ }^{14}$ Behm, vๆotí, ThWNT IV 931s. La tradición talmúdica babilonense establece que Esdras decretó que la Torá debía leerse los lunes y jueves (m.Meguilá 3,6; 4,1; t.Meguilá 4 (3),10; tp.Meguilá IV, 75a; Tratado Soferim 10,1; tb.Bava Kama 82a y otros).

${ }^{15}$ Los habitantes de las aldeas celebraron la fiesta de Purim el lunes o jueves más cercano al catorce de Adar. La explicación dada para esta costumbre es que no había nadie en las aldeas que pudiera leer el rollo de la Megillah para la comunidad y tal vez ni siquiera llegaban a completar el número requerido para la "asamblea". El lunes y el jueves fueron elegidos porque eran "días de asamblea" (m.Meguilá 1,1). Los talmudes aducen otra razón que indica que estos días fueron elegidos porque los residentes de las aldeas agrícolas acudían a las ciudades para abastecer los mercados con productos frescos (tp.Meguilá I,70b; tb.Meguilá 4b)

${ }^{16}$ Ze'ev Safrai, The Economy of Roman Palestine, Routledge, London - New York $1994,44.135 \mathrm{~s}$ 
Meguilá, esta no tenía por qué realizarse en los antiguos días de mercado, lunes o jueves.

De lo anteriormente expuesto, parece claro que los lunes y los jueves eran días de mercado y "asamblea" ${ }^{17}$. La relación entre el día del mercado y de los tribunales, por un lado, y la lectura de la Torá, por otro lado, tiene sentido en la medida en que en esos días se congregaba gran cantidad de personas provenientes de las aldeas y se podía enseñar a la gente. Sin embargo, es difícil ver cómo se asociaron los días de mercado con los días de ayuno. Generalmente, la gente de las aldeas identifica los días de mercado con un momento especial para ir a la ciudad, atribuyéndole un sentido festivo. Incluso el mercado mediterráneo se caracteriza por intentar convencer al cliente ofreciéndole una degustación del producto cuando se trata de productos comestibles, lo que difícilmente encajaría con el ayuno. ¿Constituía el ayuno de este grupo rival una crítica al sistema de mercado y a todo lo que ello implicaba?

Al margen de la crítica o explicación económica pragmática para este tipo de abstinencia, la teología tradicional aducía para justificar este ayuno un midrash referente a los sucesos del Sinaí: “¿Con qué pasaje de la Escritura apoyaron las generaciones (anteriores) la disposición de que uno debería ayunar en el segundo y quinto día de la semana? Cuando los israelitas cometieron ese hecho (con el becerro de oro), Moisés ascendió al quinto día de la semana (al Sinaí) y descendió nuevamente el segundo día de la semana (después de cuarenta días)... Por lo tanto, los sabios decretaron que el segundo y el quinto día de la semana se debe ayunar, en los días en que Moisés subió y bajó" ${ }^{18}$. Según el Seder 'Olam Rabba § 6, Moisés descendió del Sinaí el 17 de Tamuz y rompió las tablas, convirtiéndose en un día permanente de ayuno para el pueblo judío ${ }^{19}$.

${ }^{17}$ Ismar Elbogen, Der jüdische Gottesdienst in seiner geschichtlichen Entwicklung, Georg Olms Verlag, Hildesheim 199533, 76s.; L. Ginzberg, A Commentary on the Palestinian Talmud, Vol. 1, New York 1941/1971, 402, n. 7. Por su parte, S. Lowy, "The Motivation of Fastering in Talmudic Literature", JJS 9 (1958) 19-38, p. 28, defiende el influjo del ayuno de lunes a jueves de los "componentes de la representación" en el templo para la elección del ayuno bisemanal. Esta explicación, sin embargo, no es satisfactoria, ya que un ayuno bisemanal difícilmente puede explicarse mediante un ayuno puntual de cuatro días.

${ }^{18}$ TanB (Tanhuma Buber) Way-yera $\S 16$.

${ }^{19}$ Heinrich W. Guggenheimer, Seder Olam. The Rabbinic View of Biblical Chronology, Rowman \& Littlefield Edition, Lanham 2005, 73. 
De lo expuesto anteriormente, se puede concluir que los lunes y jueves eran días de ayuno practicado por algún grupo judío piadoso - rigorista frente a los días de mercado y posteriormente se intentó justificar la elección de esas fechas mediante explicaciones teológicas como pudiera ser una señal de arrepentimiento por los pecados cometidos por el pueblo en tiempo de Moisés.

Otra orientación diferente en la investigación ha sido el estudio de la importancia de los calendarios empleados en Israel. Los lunes y jueves parece ser que tendrían un significado especial en el contexto del calendario solar: el estado del sol determina el curso de los años y los días $(J u$ bileos II,8; el libro astronómico de Enoc (en etiópico) ${ }^{20}$, Qumrán ${ }^{21}$ ). Jubileos VI, 23-32, detalla el relato de la revelación de este calendario a Noé por el ángel:

"El total de los días de esta regla son cincuenta y dos semanas, todas las cuales hacen un año completo. Así se inscribió y fijó en las tablas celestiales, sin pasarse de un año a otro. Ordena tú a los hijos de Israel que guarden los años por este cómputo: 364 días el año completo y que no alteren las fechas de sus días y sus festividades, pues todo les acontece según su testimonio; no pasen un día ni alteren festividad. Si infringen esto y no las celebran según se les ordenó, alterarán todas las fechas, y los años quedarán también desajustados... Olvidarán las festividades de la alianza y seguirán, con las fiestas de los gentiles, sus errores y su insipiencia. Habrá quienes observen el aspecto de la luna; pero esta varía las estaciones y se adelanta a los años...”22.

Lo esencial aquí es que una vez fijada cada fecha, esta cae siempre en el mismo día de la semana y, como consecuencia, las fiestas no son movibles, ni colisionan con el sábado, ya que, según las investigaciones seminales de A. Jaubert, los días festivos en los que, entre otros, tampoco se

${ }^{20} 1$ Henoc 72,32; 74,10-17; 75,2; véase el apéndice de Otto Neugebauer, "The 'Astronomical' Chapters of the Ethiopic Enoch (72 to 82)", en: Matthew Black (ed.), The Book of Enoch or 1 Enoch (SVTP 7), Leiden 1985, 386-419.

${ }^{21}$ 4Q252 II:3 y 11Q5 XXVII:5-6. J.T. Milik (Ed.), The Books of Enoch, Aramaic Fragments of Qumrân Cave 4, Clarendon Press, Oxford 1976, 274ss.

${ }^{22}$ Jubileos VI 30-36. Véase el comentario de James C. VanderKam, Jubilees 1. A Commentary on the Book of Jubilees Chapters 1-21 (Hermeneia), Fortress Press, Minneapolis 2018, 326-328. 
puede ayunar, generalmente caían en domingos, miércoles y viernes ${ }^{23}$. Por lo tanto, el lunes, el martes y el jueves se consideraron como posibles días de ayuno, y dado que probablemente no se quiso elegir dos días consecutivos, solo quedaban libres el lunes y el jueves como días de ayuno semanales.

Según el texto mencionado de Jubileos VI, $38^{24}$, quienes no se adhirieron al calendario solar de 364 días, siguieron un calendario lunar, que contenía aproximadamente 365 1/2 días. El calendario solar no era una novedad, sino que representa un calendario más antiguo, proveniente de la época persa. El otro calendario luni-solar de más de 364 días, contra el que polemizó el libro de los Jubileos, haría referencia al calendario seléucida, que Jasón y Menelao intentaron introducir bajo el gobierno de Antioco Epifanes con el objeto de helenizar Jerusalén. En este contexto histórico, tal vez, tengamos que situar el razonamiento del ayuno de dos veces por semana conforme al texto de Soferim $21,1^{25}$, donde se dice que los alumnos de los sabios ayunaban los lunes y jueves a causa de "la profanación del nombre divino y del honor de la Torá, que ha sido quemada"' Esta actitud es comprensible a la luz de la persecución religiosa decretada en tiempos de Antíoco Epifanes, quien, según 1 Mac 1,39, "rompió y quemó los libros de la ley de Dios" después de haber transformado previamente el templo en un santuario helenístico por medio de la "abominación desoladora" (1 Mac 1,57). Así pues, el ayuno habría tenido originalmente un sentido penitencial.

${ }^{23}$ A. Jaubert, «Le calendrier des Jubilés et de la secte de Qumran. Ses origines bibliques», VT 3 (1953) 250ss, especialmente 258-262; «Le calendrier et les jours liturgiques de la semaine", VT 7 (1957) 35-61. Una valoración crítica de los resultados de esta investigación y su aplicación a los libros bíblicos en J. M. Baumgarten, "The Calendar of the Book of Jubilees and the Bible", en: J. M. Baumgarten, Studies In Qumran Law (SJLA 24), Leiden 1977. En parte se ha desdicho de sus críticas en "Some problems of the Jubilees Calendar in current research", VT 32 (1982) 484-489.

24 "Por eso yo te ordeno y te conjuro que les exhortes, pues tras tu muerte, tus hijos se corromperán, no computando años de solo 364 días, con lo que equivocarán el novilunio, la estación, las semanas y las festividades, y comerán la sangre de toda carne". Stephane Saulnier, Calendrical Variations in Second Temple Judaism. New Perspectives on the 'Date of the Last Supper' Debate, Brill, Leiden - Boston 2012, 163-203.

${ }^{25}$ Felix Böhl, "Das Fasten an Montagen und Donnerstagen. Zur Geschichte einer pharisäischen Praxis (Lk 18,12)" BZ 31 (1987) 247-250. Sorprende que no se mencione la destrucción del templo; solo el capítulo 13 del Rollo del ayuno, un añadido posterior, aduce la destrucción del templo como motivo del ayuno bisemanal. 
En conclusión, las tradiciones más antiguas no proporcionan un motivo único para que fueran elegidos el segundo y quinto días como fechas de ayuno público, y como J.-P. Audet indicó, sería aventurarse invocar interpretaciones más tardías ${ }^{26}$. Al margen del origen histórico de la elección de esas fechas por algunos grupos judíos, la Didajé afirma taxativamente que se deben evitar el segundo y el quinto día y en su lugar prescribe ayunar el cuarto y el sexto.

\section{2. El ayuno de la comunidad de la Didajé: el cuarto y sexto día de la semana}

En contraste con la polémica del evangelio de Mateo contra los fariseos (Mt 6), la instrucción sobre el ayuno en Did 8 no se relaciona con el secreto de la acción o el motivo del mismo, sino que se centra solo en los días de su realización. El ayuno tiene un significado social y religioso, porque impide la oportunidad de compartir una comida común. Si las personas ayunan "públicamente" al mismo tiempo, entonces este acto tiene una dimensión social, en cuanto que produce la cohesión del grupo frente a los que no pertenecen al mismo. Regulando este rito, la Didajé quiere asegurar que su círculo se distinga de otros que realizan la misma práctica, aunque de manera diferente. Por eso el didajista prohíbe a los miembros de su comunidad participar en el ayuno de otras agrupaciones. ¿Por qué escogió precisamente esos días sustitutivos? ¿Tenían algún significado especial? Se han aducido diversas razones. Veamos algunas.

Según algunos eruditos, ya que el autor de la Didajé tenía como objetivo definir la identidad de su comunidad en contraste con los judíos de la sinagoga, que ayunaban los lunes y jueves, no le quedaba más opción que los martes - viernes o miércoles - sábado ${ }^{27}$.

${ }^{26}$ Jean-Paul Audet, La Didachè. Instructions des Apôstres, J. Gabalda, Paris 1958, 368.

${ }^{27}$ R. Knopf, Die Lehre der zwölf Apostel. Die zwei Clemensbriefe (HNT.E 1), Tübingen 1920, 23, intentó demostrar que el martes o el miércoles y el viernes eran las únicas alternativas posibles a los días de ayuno judíos. Sin embargo, la elección precisa de los días en la Didajé todavía no está clara.

${ }^{28}$ Marcello del Verme, Didache and Judaism 176-86; cf. también Peter J.Tomson, "Halakhic Evidence of Didache 8 and Matthew 6 and the Didache Community's Relationship 
Marcello del Verme propone otra interpretación diferente ${ }^{28}$. Did 8,1 reflejaría un conflicto de distintos calendarios (lunar, luni-solar o solar) adoptados por dos grupos diferentes ${ }^{29}$. En las comunidades de la Didajé (después del año 70 d.C.), existirían simultáneamente grupos rivales adheridos al mismo movimiento de Jesús. Estos grupos cristianos judíos transfirieron una problemática específica judía al nuevo contexto comunitario (cúltico y ético) del "judaísmo cristiano". Eran personas o grupos que habían vivido anteriormente en un clima de tensión entre ellos mismos: un grupo de origen farisaico (hipócritas) y los "otros" (los verdaderos miembros de la comunidad) de descendencia esénica -henóquica- apocalíptica. Ambos grupos intentaban encontrar su propia identidad en la nueva situación comunitaria del judaísmo cristiano. Este último grupo acusó a los hipócritas de ser malvados y disidentes (= hipócritas), porque habían escogiendo el lunes y el jueves como días de ayuno, perpetuando con ello el antiguo error farisaico (hipocresía). "Los otros" celebraban las fiestas en miércoles y viernes (y el domingo) conforme al calendario $\operatorname{solar}^{30}$. El ayuno conforme a un calendario concreto podría constituir un indicador importante para recuperar la identidad perdida de algunos grupos judíos que no renunciaron a sus prácticas (cúlticas ni rituales) ni a su comportamiento social y moral, cuando se convirtieron al cristianismo. Contra esta hipótesis de Marcello debemos aducir, sin embargo, que no disponemos de información referente a disputas acerca del calendario solar/lunar dentro de la comunidad cristiana. El texto de la Didajé no indica que hubiera dificultades en la celebración del día del Señor $(14,1)$

to Judaism", en: Huub van de Sandt (ed.), Matthew and the Didache. Two Documents from the Same Jewish-Christian Milieu?, Van Gorcum, Assen 2005, 135-37.

${ }^{29}$ Annie Jaubert, «Jésus et le calendrier de Qumrân», NTS 7 (1960-61) 1-30; La date de La Cène. Calendrier biblique et liturgie Chrétienne, Ebib, Gabalda, Paris 1957, 13-75; Josef Blinzler, "Qumran-Kalender und Passionschronologie", ZNW 49 (1958) 243-44. Huub van de Sandt - David Flusser, Didache 293, consideran la posibilidad de la elección de esos días de ayuno por influencia de Qumrán: "The choice of the primitive church may also have been influenced by the use of the solar calendar among the Jewish sect of Qumran". Contra esta hipótesis se expresa Kurt Niederwimmer, Die Didache (KAV 1), 2. ergänzte Auflage, Vandenhoeck \& Ruprecht, Göttingen 1993,167,n.16, al considerarla muy improbable: "Alles sehr unwarhscheinlich", que los debates acerca del calendario sean la razón de la elección de los días de ayuno en la Didajé.

${ }^{30}$ Marcello del Verme, Didache 184s. 
frente al sábado, lo que denota que el calendario no planteaba dificultades.

Existen también interpretaciones que tienen en consideración las implicaciones económicas y sociales del ayuno. No era deseable practicarlo en los días de mercado, porque reducía la demanda y provocaba la caída de los precios. Es como si existiera un conflicto entre los intereses económicos y algunos aspectos religiosos acerca de los días de mercado en los que algunos grupos ayunaban (m.Ta’an 2,9). ¿Participó el didajista en esta discusión? Según Jürgen Zangenberg, quienes dependían del mercado de la ciudad no veían con buenos ojos que se ayunara el lunes y el jueves. Pudiera ser que el didajista rechazara esos días porque aceptaba el punto de vista de los habitantes de las ciudades que se beneficiaban de los días de mercado cuando los habitantes de las aldeas bajaban a la ciudad para vender sus productos y comprar otros. Por este motivo cambió los días de ayuno, eligiendo precisamente el viernes, día de mercado en las aldeas ${ }^{31}$. Si esto es así, "la Didajé rechazaría los días de ayuno para estar en sintonía con los intereses de la comunidad urbana en la que estaba inmersa su congregación, no para romper con ella. La Didajé promovería aún más su piedad a costa de los contactos con los habitantes de las aldeas (quienes serían considerados hipócritas)" ${ }^{\prime 32}$. ¿Y por qué se debe ayunar los miércoles? ¿Sería porque sigue una práctica hipotética judía de ayunar los miércoles, los viernes y los domingos?

Los autores modernos consideran que se nos escapan las razones para la elección del miércoles y viernes como alternativas de ayuno y es difícil invocar interpretaciones más tardías. ¿Se debe suponer entonces que los redactores de la Didajé eligieron los días alternativos al azar? Según Aaron Milavec, no completamente ${ }^{33}$. Ya hemos mencionado la regla de no elegir un día antes o después de una fiesta. En Did 8, se concluye que la eucaristía era una fiesta celebrada las noches del sábado, el primer día de la semana según el cómputo judío. Siendo este el caso, el día antes y después serían días inadecuados para el ayuno. Este hecho deja como

${ }^{31}$ Los mercados de las villas tenían lugar los viernes (la víspera del Sabbat). La Tosefta en Baba Metzi'a 3,20.78, afirma: "Por eso es habitual que el mercado se celebre en las ciudades pequeñas o villas de un viernes a otro".

${ }^{32}$ Jürgen K. Zangenberg, "Reconstructing" 57.

${ }^{33}$ Aaron Milavec, The Didache. Faith, Hope, and Life of the Earliest Christian Communities, 50-70 C.E., The Newman Press, New York - Mahwah, N.J. 2003, 294s. 
posibilidades el tercer, cuarto, quinto y sexto día de la semana. Como el quinto corresponde a los hipócritas, esa fecha tampoco es elegible. Por otra parte, la elección de dos días consecutivos habría requerido un ayuno demasiado severo para la mayoría de los miembros de las comunidades de la Didajé. Así pues, cuando se consideran todos los factores, la elección se reduce a las siguientes fechas: al tercero y sexto o al cuarto y sexto. ¿Estas dos posibilidades tenían las mismas opciones y relevancia?

Annie Jaubert cree que la elección del cuarto día pudo deberse a la importancia dada a ese día en el calendario solar ideado por la comunidad judía cuya biblioteca fue depositada en Qumrán. El calendario de estas comunidades era el siguiente: Cada año constaba de doce meses de treinta días cada uno, más cuatro días adicionales, de los cuales se intercalaban uno al final de cada trimestre. El día de Año Nuevo y el primer día de trimestre caían en miércoles. El miércoles era un día especial, pues constituía el primer día según el orden de la creación, ya que las luces celestiales (sol, luna y estrellas, la base de cualquier calendario) se crearon en el cuarto día (Gen 1,14-19).

La debilidad de la hipótesis de Jaubert, en opinión de Aaron Milavec, es que el cuarto día no se asoció con el ayuno y que no se ha demostrado que las comunidades de Qumrán influyeran en las comunidades de la $D i$ dajé. No obstante, Jaubert llama la atención sobre el hecho de que un segmento del judaísmo podía crear un calendario independiente para su propio uso. "Dado el hecho de que las comunidades de Qumrán se sintieron en desacuerdo con el resto del judaísmo, la elección de un calendario alternativo sirvió para demostrar y enfatizar su separación... La discusión anterior arroja luz sobre por qué ciertas elecciones se pasaron por alto, pero la elección precisa del tercer y sexto día sobre el cuarto y sexto nos elude" 34 .

Como en el caso del Talmud babilónico, la tradición posterior cristiana proporcionó razones para explicar aspectos que la tradición anterior dejó sin aclarar. Así las Constituciones apostólicas (380 d.C.) aducen el motivo de la elección del cuarto y el sexto días como fechas de ayunos: "En el cuarto día, la condena del Señor vino con Judas prometiendo la

${ }^{34}$ Aaron Milavec, Didache 295. 
traición por dinero; ... el día de la preparación del sábado, el Señor sufrió su pasión a través de una cruz de manos de Poncio Pilato" $(7,23,2)$.

Estos últimos desarrollos no pudieron haber existido en el primer siglo. Solo después de que se crearan las narraciones de la pasión y se instituyeran los días festivos cristianos para conmemorar el evento clave en la vida de Jesús, esas motivaciones se pudieron aplicar al ayuno bisemanal preexistente.

Cualquiera que fuera la razón para escoger esos días, lo cierto es que el debate se movía dentro del ámbito judío. Introduciendo el cambio de días de ayuno, el didajista trató de establecer fronteras en base a un campo común de prácticas. Pero sería una forma de judaísmo diferente al de los hipócritas al adoptar varias medidas innovadoras, como era también el contenido de la oración - el Padrenuestro, y la celebración dominical (Did 14).

Además de algunas consideraciones prácticas, como no ayunar dos días consecutivos, es probable que estos días hayan sido elegidos con el único propósito de distinguir a las comunidades cristianas de las de los hipócritas con las que se encontraban en contacto y al mismo tiempo en tensión. El didajista busca distanciarse de esas comunidades ${ }^{35}$.

\section{La modalidad propuesta de ayuno}

Mientras que la Didajé prescribe las fechas del ayuno, sin embargo no indica el modo de llevar a cabo dicha abstinencia. ¿En qué consistía ese ayuno? ¿Implicaba la abstinencia total o parcial de alimento sólido? Si era parcial, ¿qué alimentos y en qué cantidad se permitía? En caso de que fuera ayuno total, ¿también incluía la abstinencia de bebidas, incluso de agua? ¿Implicaba el ayuno abstenerse de otras prácticas, como eran los juegos, relaciones sexuales o baños? ¿Iniciaba el ayuno a la puesta del sol y tenía una duración de 24 horas o solo durante el periodo diurno?

${ }^{35}$ Huub van de Sandt - David Flusser, Didache 295-96. Véase también Huub van de Sandt, "Was the Didache Community a Group within Judaism? An Assessment on the Basis of Its Eucharistic Prayers", en: Marcel Poorthuis et. al. (eds.), A Holy People. Jewish and Christian Perspectives on Religious Communal Identity (JCPS 12), Brill, Leiden 2006, 85107.

${ }^{36}$ Aaron Milavec, Didache 298. 
Dadas las raíces judías de la Didajé, Aaron Milavec ${ }^{36}$ supone que los miembros de la Didajé observaron su ayuno de la misma manera que lo hicieron los judíos de su época. Examinando las prácticas judías de ayuno conocidas, se encuentra una gran variedad de circunstancias y no existía un estándar uniforme de severidad del ayuno en las tradiciones bíblicas o en la Misná. Por lo cual parece lógico concluir que la Didajé igualmente aplicó la sindéresis y la prudencia cuando se trataba de ayunar. Esto se puede deducir no solo del hecho de que no se dieron reglas que definan el rigor del ayuno, sino que, además, cuando se exhorta a ayunar en solidaridad con los bautizandos, la Didajé insinúa que se haga en la medida de las posibilidades particulares $(7,4)$. Presumiblemente, los miembros de esas comunidades, a nivel personal, sopesaron sus propias fuerzas a la hora de realizar el ayuno y actuaron en consecuencia. Se puede suponer que el ayuno realizado después del bautismo siguió los mismos parámetros establecidos para el iniciando en su ayuno prebautismal. Si este fuera el caso, sería más natural que no se definiera una regla estricta y rigurosa que regulara la severidad del ayuno, ya que cada uno debía sopesar sus posibilidades teniendo en consideración las diferentes circunstancias.

\section{La identidad de los hipócritas}

¿Quiénes eran estos "hipócritas"? ${ }^{37}$ ¿Qué grupo fue el objeto de esta acusación? Existen cinco textos que contienen alguna palabra relacionada

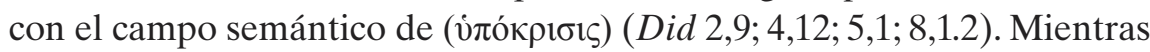

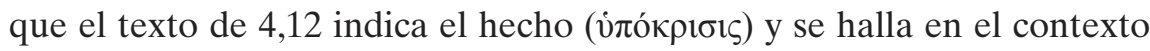

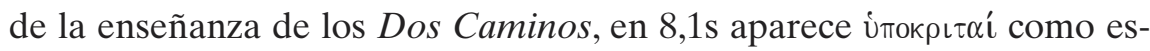
tigmatización de un grupo en competencia. El NT sigue generalmente el uso de los LXX refiriéndose a una persona cuya actitud no es determinada por las normas de Dios, convirtiéndose en una persona impía ${ }^{38} \mathrm{o}$ apóstata.

${ }^{37}$ El término implica connotaciones negativas, incluyendo desviación, deshonestidad, apostasía, expresando el contraste entre dos grupos; cf. Niederwimmer, Die Didache 165 66; J.A. Draper, "Do the Didache and Matthew Reflect an 'Irrevocable Parting of the Ways' with Judaism?", en: H. van de Sandt (ed.), Matthew and the Didache 217-41, esp. 230-31.

${ }^{38}$ Horst Balz - Gerhard Schneider, Diccionario Exegético del Nuevo Testamento, vol. II, Sígueme, Salamanca 1998, 1890s. 
Este uso negativo del término aparece también en Josefo y Filón. En la literatura judía de la diáspora, la palabra es utilizada, con pocas excepciones, en sentido negativo ${ }^{39}$ y la Didajé emplea el término en un sentido general para caracterizar a su adversario como impío. En el NT, el sustantivo agente viene utilizado en los evangelios sinópticos (Mc, una vez; Lc, 3 ocasiones; Mt, 14 recurrencias). El uso de este término es típico en Mt (cf. 23,13.15s.23.25.27.29), y llega a ser un concepto polémico que representa una categoría ética. Es en este contexto donde se debe interpretar el concepto hipócrita de Did 8,1.

Una comparación entre ambos textos muestra que el término "hipócrita" tiene connotaciones diferentes en Did 8 y Mt 6. Mientras que en Mt 6,16 se critica la praxis de los hipócritas porque no es sincera, Did 8,1 recuerda que el ayuno se debe realizar en días diferentes a los hipócritas. Mt se interesa por un comportamiento ético mientras que la Didajé por el momento de realizarlo, reestructurando el ritual ${ }^{40}$.

Semejantes diferencias existen también respecto a la oración. Mt critica la praxis de la oración de los hipócritas porque ellos oran en las esquinas de las calles y en lugares especiales de las sinagogas para ser vistos; rezan para mostrar en público su piedad. Did 8,2-3 no critica la praxis, ni dice nada acerca del tipo de oración de los hipócritas, sino que propone una oración alternativa como signo diferenciador respecto a la oración de los hipócritas. Esto es claro en la exigencia de rezar exclusivamente el $\mathrm{Pa}-$ drenuestro tres veces al día, frente a los textos establecidos que rezaban regularmente, tres veces al día, los hipócritas. Por lo tanto, la Didajé no aborda la cuestión de la exigencia ética de la oración como muestra de sinceridad, sino la selección del texto adecuado para orar. De estas observaciones, podemos concluir que los hipócritas en Did 8,1ss no están relacionados con los problemas éticos, sino que el concepto es una etiqueta para un grupo sociológico. Surge la pregunta, ¿a qué grupo religioso se le designa con el vocablo "hipócrita"?

Las indicaciones señaladas, en principio, no excluyen la identificación de los hipócritas con los gentiles, lo cual sería posible a tenor del título

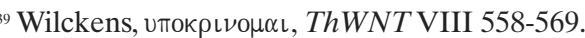

${ }^{40}$ Gunnar Garleff, Urchristliche Identität in Matthäusevengelium, Didache und Jakobusbrief (BVR 9), Lit Verlag, Münster 2004, 119: "Im MtEv geht es um eine ethische Haltung, während die Didache rituelle Umschichtungen vornimmt". 
largo del documento, "Doctrina del Señor a las naciones por medio de los doce Apóstoles". Se podría pensar que los gentiles convertidos debían ayunar y orar para separarse de su ambiente gentil. Sin embargo, es improbable que el didajista adscribiera a los gentiles esta piedad positiva de ayunar dos días por semana y orar tres veces al día. Por el contrario, consideramos que nos encontramos ante una praxis judía.

Excluida la identificación de los hipócritas con los gentiles, varios autores han buscado a los hipócritas dentro de las mismas comunidades cristianas, por lo que el didajista afrontaría un conflicto intracomunitario. Así W. Rordorf - A. Tuilier ${ }^{41}$ estudiaron la identificación de los hipócritas con los judíos y consideraron improbable que un documento como la Didajé, que debe tanto a la tradición judía, se haya expresado de forma tan violenta contra los judíos. Además, según el contexto, el concepto "hipócrita" debe haber sido aplicado a un grupo de disidentes de la comunidad del didajista que recomendaba ayunar y orar según la forma de los judíos. Did 8 condenaría la actitud de algunos cristianos judaizantes, denunciando especialmente el regreso a las observancias judías dentro de las comunidades cristianas. Pero si consideramos la proveniencia judeocristiana del autor de la Didajé, es improbable que haya empleado ese término para denostar a otro grupo judeocristiano.

Marcello del Verme ${ }^{42}$ también interpreta el conflicto como una disputa interna, según hemos visto anteriormente. Según él, los hipócritas constituirían un grupo cristiano de origen farisaico que ayunaba siguiendo un calendario diferente a los cristianos de origen esénico - henóquico. El argumento, entonces, giraba en torno a la cuestión del ayuno en un contexto de grupos rivales judíos, que se habían adherido a las enseñanzas de Jesús. Ambas agrupaciones estaban buscando su propia identidad en la

${ }^{41}$ Willy Rordorf - André Tuilier, La doctrine des douze Apôtres (Didachè) (SChr 248), Du Cerf, Paris 1978, 37, sugieren que los hipócritas eran cristianos judaizantes disidentes, es decir, cristianos judíos que se suscribieron a las prácticas rituales del judaísmo. Para argumentos en contra de esta posición, véase Klaus Wengst, Didache (Apostellehre), 29-30, n. 109. Por su parte, Aaron Milavec, The Didache 304-6; 800-2, considera que los hipócritas eran judíos y cristianos judíos que defendían la piedad del templo entre los conversos gentiles.

${ }^{42}$ Marcello del Verme, "Who are the people labelled as 'hypocrites' in Didache 8? A propos of fasting and tithing of the 'hypocrites': Did 8:1(-2); Matt (par. Luke 11:42); and Luke 18:11-12”, Henoch 25 (2003) 321-360; Idem, Didache and Judaism 185. 
nueva situación comunitaria del judaísmo cristiano. Aquellos judíos cristianos que conservaban la tradición enóquica (representada por el editor de la Didajé) acusaron a los íлокрı $\alpha i ́$ de ser disidentes al considerar el lunes y el jueves elegibles como días de ayuno, ya que perpetuaban el antiguo error farisaico ("hipocresía"). Preferían los días del miércoles y viernes como días de ayuno debido a su particular importancia en el antiguo calendario solar. No obstante, esta hipótesis es cuestionable ante la ausencia de testimonios referentes a discusiones internas acerca del calendario, pues no planteaba ninguna dificultad celebrar el día del Señor en domingo (Did 14,1), ni se necesitó justificar dicha fecha. Nada se dice sobre las celebraciones cúlticas en sábado. Por ello, tenemos que excluir la identificación de los hipócritas con judíos cristianos.

¿Quiénes son pues los hipócritas para la comunidad de la Didajé? Muchos autores piensan que el didajista se refiere a judíos piadosos en general ${ }^{43}$. Sin embargo, Helmut Köster ha demostrado que el vocablo "hipócritas" no es una designación general para los judíos, ni existen testimonios para tal uso, exceptuando $\mathrm{Mt}^{44}$. Por su parte, Gunnar Garleff considera que las críticas en 8,1 ss van dirigidas contra la praxis del ayuno y la oración, por lo que los hipócritas se deben hallar entre los grupos judíos. Teniendo en cuenta el término en Did 4,12, donde el didajista identifica a los hipócritas con quienes no son agradables a Dios, concluye: "Me

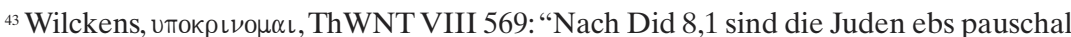
die ن́токрı $\alpha$ í wie in rabb Texten die Christen”. J.-P. Audet, Didachè 368: «Les 'hypocrites' ce doit donc être ici, comme à 8:2, tous ceux des Juifs, pharisiens ou autres, qui ont refusé et qui refusent encore de croire en l'évangile». Kurt Niedewimmer, Die Didache 166: „Gemeint sind damit an unserer Stelle wohl allgemein die Frommen Israels, schwerlich speziell die Pharisäer"; H. van de Sandt - David Flusser, Didache 292: "Because the Didache does not critize the type but the time of fasting, there is no need to see this expression as intended for Pharisees in particular. The hypocrites in Did 8:1 probably is a general reference to (pious) Jews". Cf. R. Knopf, Die Lehre 23; Klaus Wengst, Didache (Apostellehre), Barnabasbrief, Zweiter Klemensbrief, Schrift an Diognet, Kösel-Verlag, München 1984, 29-34; Clayton N. Jefford, The Sayings of Jesus in the Teaching of the Twelve Apostles, Brill, Leiden 1989, 102, n. 25 y 106.

${ }^{44}$ Helmut Koester, Synoptische Überlieferung bei den apostolischen Vätern (TU 65), Akademie-Verlag, Berlin 1957, 203.

${ }^{45}$ Gunnar Garleff, Urchristliche Identität 122. 
parece que con la designación del grupo o grupos judíos en competencia se refiera a grupos impíos o no gratos a Dios" ${ }^{45}$.

Para Jonathan A. Draper ${ }^{46}$, el concepto "hipócritas" parece referirse a los fariseos o al rabinismo naciente, ya que no hay evidencias de que los judíos piadosos 'en general' ayunaran el lunes y el jueves y oraran tres veces al día ${ }^{47}$. La palabra 'hipócrita' en Did 8,1-2 no va dirigida contra el judaísmo, sino que expresa la oposición de una comunidad judía a la práctica del movimiento rabínico naciente. La designación de los judíos fariseos como hipócritas es un indicador de la cercanía de la comunidad de la Didajé a sus raíces judías, ya que acepta el acto mismo del ayuno, pero afirma que el ayuno de la comunidad debe tener lugar en días distintos, sin aducir razones. Ello implica que la comunidad ayunaba anteriormente en los mismos días que los hipócritas, pero las fechas fueron cambiadas deliberadamente para establecer una distinción frente a otros grupos judíos con quienes estaban en contacto y rivalidad. También utilizaba el Padrenuestro litúrgicamente, como demuestra la doxología y el amén. La exhortación emplea estas dos prácticas existentes para diferenciar la comunidad cristiana y sus adversarios, los judíos fariseos. La repetición del Padrenuestro debe reafirmar la diferencia de la comunidad frente a otros grupos judíos que también exigían recitar tres veces al día la oración $T e$ filla que se cristalizó en el Semoneh Esreh. La recitación pública de la oración habría separado una comunidad de otra en Israel, como acontecía con la comunidad de Qumrán, que oraba dos veces al día (1QS 9,26-10,5). Los fuertes acuerdos entre Mateo y la Didajé, afirma Jonathan A. Draper

${ }^{46}$ Jonathan A. Draper, "Christian Self-Definition against the 'Hypocrites' in Didache 8", en: J. A. Draper (ed.), The Didache in Modern Research (AGAJU 37), Brill, Leiden New York - Köln 1996, 233-238. Idem, "Do the Didache and Matthew Reflect an 'Irrevocable Parting of the Ways' with Judaism?, en: Huub van de Sandt (ed.), Matthew and the Didache 230-235.

${ }^{47}$ En contra de esta identificación con los fariseos, Aaron Milavec, The Didache 302 03 , considera que la costumbre de ayunar dos veces por semana no era en absoluto una característica de los fariseos: "Nada en los evangelios o en la Misná incluye ningún indicio de que los fariseos se distinguieran por el ayuno, mientras que el resto de la población judía no ayunaba o ayunaba en días diferentes" (302s). Concluye que "cuando se realizaba un ayuno público, por lo tanto, era evidente que los judíos que se reunían, ayunaban en solidaridad, independientemente de si eran fariseos o no". 
en un artículo sobre el tema ${ }^{48}$, permiten entrever que ambos documentos provienen de la misma comunidad judía en una fase diferente de desarro$110^{49}$.

Según P.J. Tomson ${ }^{50}$, M. del Verme y J.A. Draper, la comunidad de la Didajé aún estaba inserta dentro del judaísmo cuando se editó la Didajé. El escrito probablemente fue compuesto después de la guerra judía, en el período en que creció la influencia de los rabinos, los sucesores de los fariseos. El surgimiento e incremento del rabinismo en este período va de la mano de la consolidación de la academia rabínica en Yavne (Jamnia) y condujo a la promulgación de decisiones legales que reclamaban autoridad religiosa. Los miembros de la comunidad de la Didajé se sentían molestos por los intentos de la autoridad central judía de manejar sus vidas y les incomodaba que los rabinos tomaran el control de la esfera pública.

\section{Conclusión: El ayuno y la identidad grupal}

El autor de la Didajé pretende configurar la identidad del grupo de los seguidores de Jesús al que se dirige, afrontando para ello los desafíos que planteaban ciertas interacciones intercomunitarias e intracomunitarias. Por un lado, la comunidad de la Didajé experimentó disputas ad intra que amenazaban la estabilidad: falsos maestros que introdujeron enseñanzas en contra de las normas comunitarias, estafadores que abusaron de la generosidad de la comunidad, falta de respeto hacia los líderes co-

${ }^{48}$ J.A. Draper, "Do the Didache and Matthew Reflect"230-35;240-41. Cf. J.A. Draper, "Christian Self-Definition against the 'Hypocrites' in Didache VIII", en: idem, The Didache in Modern Research 223-43.

${ }^{49}$ Cf. ampliamente D.A. Cinera, "Didache" 132-143.

${ }^{50}$ Según Peter J. Tomson, la polémica demarcación frente a los "hipócritas" en Did 8 refleja el cisma entre la comunidad de la Didajé y los fariseos. Peter J. Tomson, "The wars against Rome, the rise of Rabbinic Judaism and of Apostolic Gentile Christianity, and the Judaeo-Christians; elements for a synthesis", en: P.J.Tomson - D. Lambers-Petry (eds), The Image of the Judaeo-Christians in Ancient Jewish and Christian Literature (WUNT 158), Tübingen 2003,1-31, esp. 9-10, n. 40; idem, "The Halakhic Evidence of Didache 8 and Matthew 6 and the Didache Community's Relationship to Judaism”, en: Huub van de Sandt, Matthew and the Didache 131-41. Michelle Slee, The Church in Antioch in the First Century C.E. Communion and Conflict (JSNTS 224), T \& T Clark, London - New York 2003, 93, argumenta que los opositores eran miembros de un grupo de fariseos cristianos que buscaban "socavar las enseñanzas del didajista". 
munitarios, discrepancias en la práctica de los rituales, disputas y rencores entre los miembros de la comunidad, delincuentes impenitentes y apóstatas. Por otro lado, la comunidad tenía que confrontarse con la cultura pagana de la sociedad greco-romana, lo cual se refleja en las instrucciones en la sección de los Dos Caminos dirigidas contra las prácticas paganas, especialmente la idolatría. Asimismo, debía establecer sus fronteras frente a otras comunidades judías que no creían en Jesús, como se ve a la hora de priorizar la tradición de Jesús en la sectio evangelica de los Dos Caminos y en las instrucciones rituales, en las que transforma tradiciones judías en prácticas cristianas, especialmente en la polémica con los "hipócritas", donde regula la práctica de algunos rituales.

Este es uno de los objetivos de la sección Did 7-10. Se instruye acerca de varios rituales importantes de la iglesia naciente: el bautismo simboliza la incorporación al grupo; el ayuno, las oraciones y las comidas eucarísticas proporcionan expresiones externas de la identidad grupal. La participación en estos rituales comunitarios distintivos sirve para establecer y manifestar socialmente las fronteras entre los miembros del grupo y las personas ajenas. En particular, dado que algunos rituales, como las oraciones y los ayunos, eran actos públicos, la participación en ellos crea una diferenciación pública entre la comunidad y otros grupos. Por lo tanto, la distinción entre el grupo de pertenencia y los grupos externos a través de la práctica de los rituales no solo es percibida y sentida por los miembros de la comunidad, sino que también es reconocida por personas externas.

Otros aspectos de las disposiciones rituales en la Didajé ayudan a delimitar los límites grupales de la comunidad. En primer lugar, la participación en los rituales es restringida. Quienes no han sido bautizados tienen prohibido participar en la eucaristía comunitaria $(9,5)$ y los miembros en disputa con otros miembros que no se hayan reconciliado también están excluidos $(14,2)$. Estas restricciones utilizan la noción de pureza para hacer cumplir los estándares de santidad que aprecian los miembros de la comunidad. Los rituales se convierten así en un recordatorio continuo para que los miembros de la comunidad cumplan con las normas grupales, que les caracterizan.

En segundo lugar, los rituales comunitarios transmiten una distinción clara entre el estado actual de los creyentes, por un lado, y su vida anterior y el estado de los no creyentes, por el otro. El ritual del bautismo es el más conspicuo a este respecto, ya que significa la muerte social del antiguo yo 
de los conversos y una separación de sus antiguos vínculos con otras comunidades. Estos efectos del rito de iniciación son reforzados mediante la participación continua en el ayuno, las oraciones y la eucaristía de la comunidad. Por lo tanto, los rituales proporcionan el sentido de una nueva vida en los participantes, lo que los aleja de la cultura y el estilo de vida que heredaron de la socialización en su vida anterior, y sustituyen una antigua identidad social por una nueva. La superioridad de la nueva vida como se transmite en los rituales desalienta a regresar a su status previo.

En estas directrices subyace una preocupación por la unidad y la cohesión del grupo. Los peligros potenciales pueden radicar en las diferentes concepciones y realizaciones de los rituales y la permeabilización de los límites del grupo al seguir las prácticas rituales de comunidades rivales. Así pues, la sección ritual de la Didajé no es simplemente una transmisión de tradiciones rituales, sino especialmente un esfuerzo por mantener la armonía de la comunidad y evitar esos peligros.

Para ello, el didajista debe clarificar específicamente las fronteras con los judíos no cristianos. Los grupos judíos competían por la reivindicación de la identidad del pueblo de Dios, al igual que lo hacía la comunidad de la Didajé. Por lo tanto, esta tuvo que clarificar sus límites frente a otros grupos judíos y enfatizar su superioridad sobre ellos. Ya se ha señalado anteriormente que la inclusión de la sectio evangelica en la sección de los Dos Caminos distingue a la comunidad de otros grupos judíos.

Sin embargo, la frontera entre la comunidad de la Didajé y otros grupos judíos se expresa más claramente en Did 8. Las prescripciones sobre el ayuno y las oraciones en ese capítulo abogan esencialmente por una separación de las comunidades judías de los hipócritas. Las prácticas del ayuno y las oraciones se eligen como puntos de partida porque son importantes costumbres ancestrales judías, cuya observancia marca la identidad judía en el período de la iglesia naciente. Por lo tanto, la diferenciación de las prácticas del ayuno y las oraciones de la comunidad de otros grupos judíos ayuda a distinguir a la comunidad de la Didajé de su entorno judío.

Varias características de las instrucciones en Did 8 sirven asimismo para demarcar claramente los límites del grupo entre la comunidad de la Didajé y otros grupos judíos. Primero, la Didajé denomina de forma despectiva "hipócritas" a los oponentes. Este término negativo denigra y descalifica a los grupos rivales, posiblemente judíos rabínicos. En segundo 
lugar, aunque no se dan explicaciones para los días propuestos de ayuno y las oraciones, la acusación de la práctica de los oponentes como hipócritas implicaría que las prácticas de la comunidad de la Didajé son superiores a las de los rivales judíos, que vienen consideradas obsoletas. Este contraste entre lo nuevo y lo viejo, lo superior y lo inferior, refuerza las fronteras entre los dos grupos. En tercer lugar, la Didajé subraya la identidad distintiva del grupo al resaltar las diferencias en los detalles de estas prácticas entre su comunidad y los grupos rivales. Para ello se subraya los diferentes días de ayuno y el contenido concreto de la oración. Esto hace posible mantener un límite definido entre los grupos a pesar de su origen común y sus semejantes praxis rituales.

Por consiguiente, para fortalecer la identidad social de los miembros del grupo, la estrategia habitual es recurrir a enfatizar el carácter distintivo positivo del propio grupo frente a otros grupos. Esto se hace, por un lado, legitimando la realidad social construida por el grupo de pertenencia y, por otro lado, distanciándose de los grupos rivales a través del desarrollo de reglas de comportamiento. Estas estrategias sociales son empleadas en la Didajé para mejorar la cohesión de su comunidad cristiana. Al enfatizar los límites entre el intragrupo y los grupos externos, la Didajé establece una base sobre la cual se define y consolida la identidad social de su comunidad. Esta base está protegida por normas grupales, en este caso rituales, que promueven y manifiestan la separación frente a grupos externos rivales. La comparación entre el grupo de pertenencia y el grupo externo rival, denigrándole con el término "hipócrita", pretende desacreditar al grupo rival, reducir la amenaza o atracción que ejercer ese grupo externo, al tiempo que refuerza la cohesión interna de su comunidad. 